\title{
An Ion Trap-Ion Mobility-Time of Flight Mass Spectrometer with Three Ion Sources for Ion/Ion Reactions
}

\author{
Qin Zhao, ${ }^{\text {a, }}{ }^{+}$Matthew W. Soyk, ${ }^{a,+}$ Gregg M. Schieffer, ${ }^{a}$ Katrin Fuhrer, ${ }^{c}$ \\ Marc M. Gonin, ${ }^{c}$ R. S. Houk, ${ }^{\text {b }}$ and Ethan R. Badman ${ }^{a, *}$ \\ a Department of Chemistry, Iowa State University, Ames, Iowa, USA \\ b Ames Laboratory, U.S. Department of Energy, Iowa State University, Ames, Iowa, USA \\ ${ }^{c}$ Tofwerk AG, Thun, Switzerland
}

\begin{abstract}
This instrument combines the capabilities of ion/ion reactions with ion mobility (IM) and time-of-flight (TOF) measurements for conformation studies and top-down analysis of large biomolecules. Ubiquitin ions from either of two electrospray ionization (ESI) sources are stored in a three dimensional (3D) ion trap (IT) and reacted with negative ions from atmospheric sampling glow discharge ionization (ASGDI). The proton transfer reaction products are then separated by IM and analyzed via a TOF mass analyzer. In this way, ubiquitin +7 ions are converted to lower charge states down to +1 ; the ions in lower charge states tend to be in compact conformations with cross sections down to $\sim 880 \AA^{2}$. The duration and magnitude of the ion ejection pulse on the IT exit and the entrance voltage on the IM drift tube can affect the measured distribution of conformers for ubiquitin +7 and +6 . Alternatively, protein ions are fragmented by collision-induced dissociation (CID) in the IT, followed by ion/ion reactions to reduce the charge states of the CID product ions, thus simplifying assignment of charge states and fragments using the mobility-resolved tandem mass spectrum. Instrument characteristics and the use of a new ion trap controller and software modifications to control the entire instrument are described. (J Am Soc Mass Spectrom 2009, 20, 1549-1561) (c) 2009 American Society for Mass Spectrometry
\end{abstract}

$\mathrm{D}$ espite the widespread use of mass spectrometry (MS) for biological analyses, further improvements in MS instrumentation are desirable, particularly in areas like proteomics [1] and characterization of large macromolecular complexes [2,3]. These instrumentation improvements provide analytical capabilities that enable new biological studies not envisioned previously.

Ion mobility (IM) $[4,5]$ has become a very useful technique for analysis of biological ions in the gas phase [6]. IM provides information about ion size and structure [7], as it rapidly separates ions based on collision cross-section, rather than just $m / z$ ratio. The use of IM to disperse a mixture of ions in time before analysis via a time-of-flight (TOF) MS, i.e., nested drift (flight) time measurements, is an important recent advance. These experiments were pioneered by Clemmer and coworkers in the mid-1990s [8], and have now been used by several other groups [9-13]. The recent Synapt ESIIMS-MS by Waters Corp. provides a commercially avail-

Address reprint requests to Dr. E. R. Badman, Hoffmann-La Roche Inc., Nonclinical Safety, 340 Kingsland St., Nutley, NJ 07110, USA. E-mail: ethan.badman@roche.com

* Current address: Hoffmann-La Roche Inc., Nonclinical Safety, 340 Kingsland St., Nutley, NJ 07110, USA.

† These authors contributed equally to this work. able instrument for gas-phase ion conformation studies by IM using a novel traveling wave approach [9].

In a series of instrumental designs, the Clemmer group has made various modifications to the initial ESI-IM-TOF, including the insertion of a collision cell between the IM drift tube and the TOF for mobility labeling experiments [14, 15], and the addition of an IT before the mobility drift tube to improve the duty cycle from the continuous ESI source [16, 17]. One publication demonstrated MS/MS capabilities with an ion trap before IM-TOF [18], but the entire instrument was not under computer control. Therefore, only relatively simple experiments were possible.

IM has been used to analyze the products of ionmolecule reactions [19], including proton transfer [20, 21], H/D exchange [22], and solvation [23-26]. In these studies, the desired reactions take place either in the atmospheric pressure ion source interface region or in the drift tube itself. Thus, only short reaction times and certain reagent ions can be used. In addition, performing reactions in the IM cell can make spectral interpretation difficult because the analysis and chemistry occur at the same time. In the current experiments, the ion/ ion reaction is decoupled from the subsequent mobility and mass analysis. Therefore, the reaction time and chemistry of reagent ions are controlled more effec- 
tively, including a wider selection of reagent ions from independent ion sources.

Gas-phase ion/ion reactions provide another dimension for bioanalysis. Pioneering work by Smith and coworkers [27, 28] was followed by a continuing series of experiments by McLuckey's group [29]. Ion/ion reactions are rapid, versatile, and can be controlled via various ion manipulation schemes. The most common type of reaction has been proton transfer to manipulate the charge states of multiplycharged ions [30] and simplify complex MS/MS spectra [31,32]. Use of product ions in low charge states can improve mass accuracy and resolution, especially with low-resolution mass analyzers. Various instruments specifically for ion/ion reactions include ones with two [33-36], three [37], or four [38] independent ion sources arranged around an IT, although use of pulsed sources and a single ion extraction system is also possible [39, 40]. Electrontransfer is another useful process, especially electrontransfer dissociation (ETD) [33, 41, 42]. ETD is now becoming widely used in proteomics and for determination of post-translational modifications. Several instruments combine an IT for ETD reactions with a high-resolution mass analyzer, for example, the modified QSTAR/TOF MS spectrometer in McLuckey's group $[43,44]$ and the hybrid linear IT/Orbitrap MS by Coon's group [45, 46].

Here we describe the first instrument to include capabilities for both ion/ion reactions and IM-TOF-MS measurements. Initial experiments and instrument characteristics are described, including use of a new ion trap controller and software to control the entire instrument. Ubiquitin is used as a test compound to compare the new results with the extensive previous studies of this protein [21, 47-52].

\section{Experimental}

Bovine ubiquitin (Sigma-Aldrich, St. Louis, MO, USA) was used without further purification. Protein concentrations were 20 to $30 \mu \mathrm{M}$ in $1 \%$ aqueous acetic acid for positive ion mode. Nano-ESI emitters were pulled from glass capillaries $(1.5 \mathrm{~mm}$ o.d., $0.86 \mathrm{~mm}$ i.d.) by a micropipette puller (P-97; Sutter Instruments, Novato, CA). Nano-ESI was performed by applying +1 to +1.2 $\mathrm{kV}$ to the protein solution via a stainless steel wire through the back of the sample capillary. Negative ions from perfluoro-1,3-dimethylcyclohexane (PDCH; SigmaAldrich) were used as the proton acceptor reagent.

\section{Instrumentation}

\section{General}

The instrument is shown to scale in Figure 1. It contains three independent ion sources: two for ESI and one for ASGDI [53]. Ions from these sources are stored in the 3D quadrupole IT for reaction. The products are separated by the IM drift tube, followed by a quadrupole-time-offlight mass spectrometer (q-TOF).

The vacuum chamber consists of an 8 in. Conflat cube, which houses the three ion sources, ion optics, and turning quadrupole deflector (TQ; Extrel, Pittsburgh, PA, USA). The cube is evacuated by a turbomolecular pump (Turbo-V550 MacroTorr, 550 1/s N ${ }_{2}$; Varian Inc., Palo Alto, CA) backed by a mechanical pump (SD-30; Varian), and is attached to a custom built rectangular chamber (304 stainless steel, $35.6 \mathrm{~cm}$ wide $\times$ $76.2 \mathrm{~cm}$ long $\times 33.0 \mathrm{~cm}$ high) that also houses the IT, IM drift tube, and quadrupole collision cell. The TOF is in an aluminum housing $(8.90 \mathrm{~cm} \times 25.4 \mathrm{~cm} \times 66.7 \mathrm{~cm})$ attached to the back of the chamber; the TOF tube is oriented vertically. The main vacuum chamber (i.e., the chamber that houses the drift cell and quadrupole

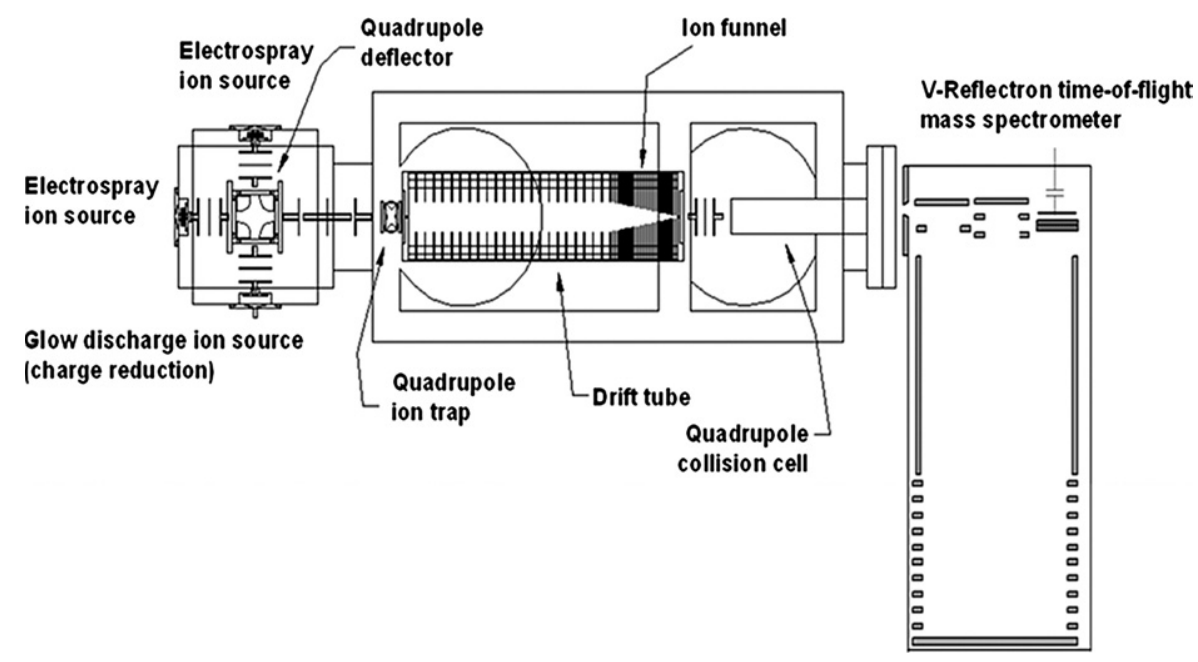

Figure 1. Scale diagram showing overall instrument, including two ESI and one ASGDI sources, ion optics, quadrupole deflector, IT, IM drift tube with ion funnel, and q-TOF. The ion source cube is 20 cm wide. 
collision cell) is evacuated by two diffusion pumps (Diffstak 250/2000M and 160/700M; BOC Edwards, Wilmington, MA, USA) backed by mechanical pumps (E2M40 and RV12, respectively, BOC Edwards). The TOF is pumped by a turbomolecular pump (Turbovac 361, 400 1/s N $_{2}$; Leybold Inc., Woodbridge, ON, Canada), backed by a mechanical pump (RV12, BOC Edwards). Convectron and ion gauges (Series 375 and 358; Helix Technology Corp., Mansfield, MA) measure the ion source and chamber pressures (all are uncorrected). The base pressures are $7.5 \times 10^{-8}$ mbar in the main chamber, and $3.3 \times 10^{-7}$ mbar in the TOF when the sources are closed. In normal operation, one ESI source and the ASGDI source are open, and helium is added to the drift tube ( $\sim 1.3$ to $2.0 \mathrm{mbar})$ through a precision leak valve (model 203; Granville Phillips, Boulder, CO, USA). The main chamber pressure is then $\sim 1 \times 10^{-4}$ mbar and the pressure in the TOF region is $9 \times 10^{-7}$ mbar.

\section{Ion Sources}

The basic design for a three ion source interface (Figure 1) has been described previously [38]. The three sources are arranged around three faces of the $8 \mathrm{in}$. Conflat cube. One source is on the ion optical axis of the IT and IM drift tube and the other two are orthogonal to it. The two ESI sources are identical. The interface region, which is $5.08 \mathrm{~cm}$ in diameter and $1.59 \mathrm{~cm}$ deep, is machined out of an 8 in. Conflat flange. A $254 \mu \mathrm{m}$ diameter aperture separates the interface region from atmosphere, and a $381 \mu \mathrm{m}$ diameter aperture separates the interface region from the high vacuum region. Two lenses between the apertures focus ions through the interface region. Each ESI interface region operates at $\sim 1$ mbar during the experiment and is pumped by a mechanical pump (E2M40; BOC Edwards). The nanoESI voltages are provided by $5 \mathrm{kV}$ power supplies (ORTEC 659; Oak Ridge, TN, USA).

The ASGDI source interface region has the same design and dimensions as the ESI sources but without the interface lenses. It is pumped by a mechanical pump (E2M40; BOC Edwards). PDCH headspace vapors are sampled via a $0.64 \mathrm{~cm}$ diameter nylon tube connecting the sample container and the outer aperture plate. The source pressure $(\sim 0.79 \mathrm{mbar})$ is regulated by a bellows valve (SS-4BMW; Swagelok, Solon, OH, USA) inserted in the tubing between the compound headspace and the source region. The ASGDI source uses a $3 \mathrm{kV}$ power supply (ORTEC 556; Oak Ridge, TN) and a high voltage pulser (PVX-4150; Directed Energy Corp., Fort Collins, CO, USA) that is trigged by a TTL pulse from the Argos IT controller (Griffin Analytical Technologies, West Lafayette, IN, USA), to apply a $\sim-420 \mathrm{~V}$ pulse between the outer and inner (grounded) aperture plates. This ASGDI pulse lasts for the time required to add reagent anions to the IT, typically 5 to $20 \mathrm{~ms}$.

Each ion source has three cylindrical lenses attached to the vacuum side of the flange to focus the ions from the exit aperture of the source into the TQ. The second lens is split in half with distinct voltages applied to each half and serves as a deflector for direction focusing. The TQ was modified by severing the electrical connection between diagonally opposing rods and by applying four independent DC potentials to the four TQ rods. This allows ions to either be deflected $90^{\circ}$ onto the axis of the instrument or to be passed straight through.

After the TQ, three lenses focus the ions into the IT. Two home-built high-voltage switches, controlled by TTL signals from the Argos IT controller, switch the voltages applied to the TQ and three subsequent lenses to allow ions from the desired ion source into the IT. Six 9-channel DC power supplies ( \pm 500 V, TD9500; Spectrum Solutions, Russellton, PA, USA) generate the potentials for the ion optics from the sources to the ion trap.

\section{Ion Trap}

The 3D quadrupole IT (ideal geometry, $\mathrm{r}_{0}=1.0 \mathrm{~cm}, \mathrm{z}_{0}=$ $0.707 \mathrm{~cm}$; RM Jordan, Grass Valley, CA) is attached to the drift tube; the exit aperture is $1.3 \mathrm{~cm}$ from the front plate of the drift tube. During ion trapping the end caps are at ground, except during resonance excitation and mass selection, and the DC potential on the ring electrode is zero to prevent any asymmetric fields. The 665 $\mathrm{kHz}$ ion trapping voltage is generated by a home-built $\mathrm{LC}$ circuit that provides up to $5000 \mathrm{~V}_{0 \mathrm{p}}$. The maximum low mass cutoff value is $\sim m / z 1220$ (calculated assuming an ideal ion trap geometry). For the work presented here, the low mass cutoff is typically $\sim m / z 200$ to allow for confinement of the $\mathrm{PDCH}^{-}$reagent anions from the ASGDI.

A 0 to $10 \mathrm{~V} \mathrm{DC}$ control signal from the Argos IT controller determines the rf trapping voltage. A custom control generates the initial low-level rf voltage, measures feedback to stabilize the rf voltage, and contains calibration data. The initial rf voltage is first amplified to 0 to $200 \mathrm{~V}_{0 \mathrm{p}}$ by a $50 \mathrm{~W}$ commercial amplifier (AG1020; T and C Power Conversion Inc., Rochester, NY, USA) and finally by the custom LC circuit to the full 0 to $5000 \mathrm{~V}_{0 \mathrm{p}}$. Measured stabilities of the full rf voltage are better than $\pm 1 \%$. A TTL input allows the rf wave to be shut off in $\sim 15 \mu$ s at any rf amplitude. The shutoff is not locked to the rf phase.

The ion trap timing and voltages are controlled by an Argos IT controller and software (see block diagram in Supplementary Information, which can be found in the electronic version of this article). The Argos provides the master clock for the entire instrument, as well as two independent arbitrary waveform outputs, digital TTL triggers, and analog control outputs (0 to $4 \mathrm{~V})$. One arbitrary waveform output provides the 0 to $10 \mathrm{~V}$ dc control signal for the ion trap rf; the other is applied to the front endcap electrode (after being amplified by $\times 17$ to $85 \mathrm{~V}_{p-p}$ ) to perform mass selection and resonance excitation. The TTL triggers are used to start the ASGDI source, control the high voltage switches for the ion 
sources, and start the ion injection pulse for the mobility experiment. A custom 8-channel driver is used to increase the power of the TTL signals to enable them to trigger $50 \Omega$ loads. The ion injection TTL pulse enables the high voltage pulser (PVX-4150; Directed Energy Corp., Fort Collins, CO, USA, applied to the exit endcap) to eject ions from the ion trap. Typically the ejection pulse for positive ions is -100 to $-150 \mathrm{~V}$ applied for 3 to $5 \mu$ s to the trap end cap closest to the drift tube (Figure 1). Two analog signals are used to control the quadrupole collision cell, described below.

\section{Drift Tube}

The drift tube (modified from a design provided by Valentine et al. [55]) consists of alternating $12.7 \mathrm{~cm}$ diameter 304 stainless steel lenses $(0.16 \mathrm{~cm}$ thick, 12.7 $\mathrm{cm}$ o.d. $4.40 \mathrm{~cm}$ i.d.) and Delrin (DuPont, Wilmington, DE, USA) insulating rings $(1.27 \mathrm{~cm}$ thick, $12.7 \mathrm{~cm}$ o.d., $8.26 \mathrm{~cm}$ i.d.). The drift tube is $44.45 \mathrm{~cm}$ long (together with the ion funnel) with a $0.5 \mathrm{~mm}$ diameter entrance aperture. A chain of $2 \mathrm{M} \Omega$ resistors connects the lenses, creating an electric field (typically $12.4 \mathrm{~V} / \mathrm{cm}$ ) down the drift tube. Unless stated otherwise, the voltage applied to the front of the drift tube is typically -30 to $-100 \mathrm{~V}$, i.e., more negative than the grounded IT. Thus, the injection voltage into the drift tube is the voltage on the entrance, and the injection energy in the lab frame is charge $\mathrm{x}$ injection voltage. A capacitance manometer (690A13TRC; MKS Instrument, Methuen, MA, USA) measures the He pressure inside the drift tube, which is typically 1.33 to $2.00 \mathrm{mbar}$, controlled via another precision leak valve.

\section{Ion Funnel}

To improve ion transmission efficiency, an ion funnel $[54,56]$ is integrated into the back of the drift tube (Figure 1). The funnel is based on the device described by the Smith [56] and Jarrold groups [57]. After the last ring of the drift tube, a series of 25 stainless steel electrodes $(0.079 \mathrm{~cm}$ thick, $12.7 \mathrm{~cm}$ o.d.) with circular apertures whose inner diameters decrease linearly from 4.293 to $0.483 \mathrm{~cm}$ is attached. The ion funnel electrodes are sealed together using $0.318 \mathrm{~cm}$ thick Delrin spacers and Viton o-rings giving a funnel length of $11.11 \mathrm{~cm}$. Thus, the helium pressure in the drift tube and ion funnel are the same. The electrodes are connected to each other with a series of resistors (Vishay, Malvern, PA, USA, $500 \mathrm{k} \Omega ; 0.6 \mathrm{~W}, \pm 1 \%$ ). One voltage is applied to the entrance of the drift tube, and a second voltage is applied to the exit of the ion funnel to set the axial electric field down the drift tube-ion funnel assembly. The electrode spacing and resistor voltages in the ion funnel are selected so that the axial electric field is the same as that in the rest of the drift tube [57].

In the ion funnel, alternate lenses are capacitively coupled (Vishay, $1000 \mathrm{pF}, 1.5 \mathrm{kV}_{\mathrm{rms}} \pm 20 \%$ ) to form two lens chains; rf voltages (Ardara RF power supply, no.
PSRF-100, Ardara Technologies, North Huntingdon, PA, USA) that are $180^{\circ}$ out of phase from each other are applied to each chain with amplitudes $\sim 90 \mathrm{~V}_{p-p}$ at 360 $\mathrm{kHz}$. A capacitor to ground decouples the rf voltage from the drift tube lenses. There is one DC only electrode after the exit of the ion funnel with a pressurelimiting aperture $(1.0 \mathrm{~mm}$ diameter $)$.

In this instrument, the ion funnel increases the overall total ion signal by a factor of $\sim 7$. Here, the basis of comparison is to a drift tube with the same overall length $(44.45 \mathrm{~cm})$ and exit aperture, but all electrodes have the same i.d. $(4.40 \mathrm{~cm})$, spacing $(1.27 \mathrm{~cm})$, and DC electric field (typically $12 \mathrm{~V} / \mathrm{cm}$ ), with no rf voltage. In this experiment, total ion signal is measured by extracting ions from the TOF extractor at high repetition rates into the flight tube and reflecting them to the TOF microchannel plate (MCP) detectors. The measured cross sections are the same whether the ion funnel is inserted or not.

Another set of three lenses behind the drift tube-ion funnel focuses ions into the quadrupole collision cell (Figure 1). The voltages supplied to the ion funnel dc lens, the lenses before the collision cell, the entrance and exit lenses of the collision cell, and the lenses between the collision cell and the TOF are floated on the drift tube exit voltage using a nine-output floating power supply (TD9500HV, Spectrum Solutions Inc., Russellton, PA, USA).

\section{Quadrupole-TOF}

The quadrupole collision cell (Figure 1) transmits ions from the ion funnel to the TOF. It also provides for CID of ions labeled by mobility (i.e., a pseudo MS/MS step) $[14,15]$, although this capability is not shown in this paper. The quadrupole $\left(\mathrm{d}_{0}=9.5 \mathrm{~mm}, 880 \mathrm{kHz}, 3600 \mathrm{~V}_{0 p}\right.$ per pole, Extrel, Pittsburgh, PA, USA) is followed by an orthogonal W-reflectron TOF (Tofwerk, Thun, Switzerland). The collision cell and its electronics are floated using an isolation transformer (SIT 30-1000, Stangenes Industries Inc., Palo Alto, CA). The collision cell is mounted on the vacuum side of an 8 in Conflat flange that is attached to the back of the main vacuum chamber. A capacitance manometer (model 690A01TRC; MKS Instrument, Methuen, MA, USA) measures the pressure inside the collision cell, which is typically $\sim 8 \times 10^{-4}$ mbar of He from the drift tube. Additional collision gas can be added via another precision leak valve. The Argos IT controller (Figure 2) supplies two 0 to $4 \mathrm{~V}$ analog signals that are amplified to 0 to $10 \mathrm{~V}$ and -200 to $200 \mathrm{~V}$, respectively, and then used by the quadrupole power supply to control the rf amplitude and to supply the dc bias to the collision cell rods to set the collision energy.

After the ions exit the collision cell, they are focused into the source region of the TOF by a series of 10 lenses mounted in the hole machined out of the $8 \mathrm{in}$. Conflat flange between the collision cell and the TOF, which is mounted vertically on the air side of the flange. One 


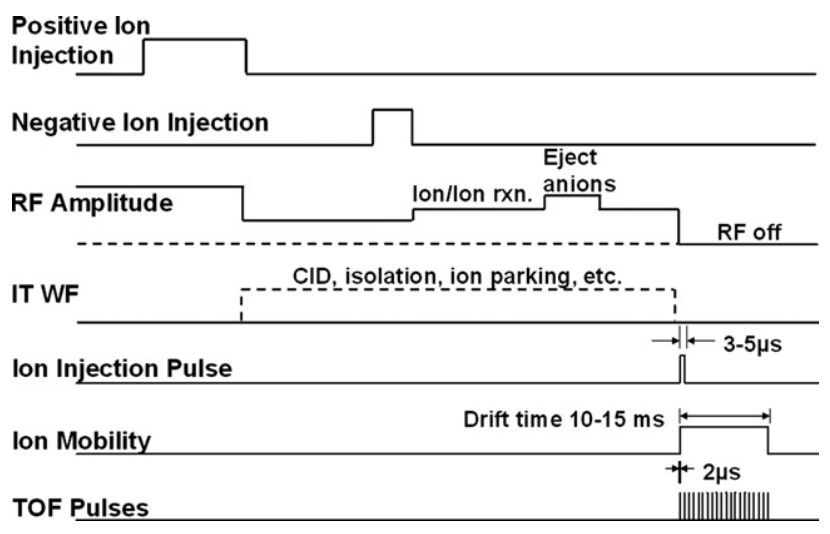

Figure 2. A generic scan function for an ion/ion reaction followed by nested flight time/ion mobility experiment. The top and second plots show the time during which positive and negative ions are injected. The third plot shows the amplitude of the rf trapping voltage applied to the ring electrode of the ion trap. The lower three plots show the times when ions after ion/ion reaction are injected into the drift tube, ion mobility data acquisition, and TOF extraction pulses.

lens is split into half-plates for vertical direction focusing. The ions are extracted upwards into the TOF drift region by a $2 \mu$ s pulse and are then accelerated into the drift region by $\sim 5800 \mathrm{~V}$. The voltages on the TOF electrodes and detector are controlled by the TOF software, which communicates directly with the TOF power supply. The TOF has a W-reflectron and can be operated in V-mode or in $\mathrm{W}$-mode. Only the V-mode is used in this paper; the effective flight path is $\sim 1.5 \mathrm{~m}$.

The ion detector is an eight-anode MCP (Ionwerks, Houston, TX, USA) that has post acceleration voltage of $\sim 6000 \mathrm{~V}$. The signal is amplified $\times 100$ by two 4 -channel preamplifiers (XCD quad amplifier/discriminator; Ionwerks) and then sent to an 8-channel time-to-digital converter $(\mathrm{TDC} \times 8$, Ionwerks). The TOF software reads the data from the TDC to create $2 \mathrm{D}$ data that contain both drift time and mass spectral information.

The timing of the TOF data acquisition (Figure 2) is similar to methods described previously $[8,16]$. As shown by the bottom three traces in Figure 2, the TOF timing controller gets signals from the software and an external trigger and sends TTL triggers to the TDC $\times 8$ and to the TOF extraction pulser. The mobility acquisition is started by the ion injection pulse (a trigger from the Argos), after which the TOF timing controller starts sending TTL triggers-at specific intervals depending on the mass range being acquired-simultaneously to the TDC $\times 8$ and the TOF extraction. In a typical experiment 100 TOF extractions are taken within each $10 \mathrm{~ms}$ mobility spectrum, up to a maximum $\mathrm{m} / \mathrm{z}$ value of 2400. Mass spectra could be measured to higher $\mathrm{m} / \mathrm{z}$ values, but there would be fewer such mass spectra over the duration of the IM peaks. Alternatively, interleaving [58] could be used to improve the number of points in the IM spectra, although this makes the data files larger.

\section{Measurement of Cross Sections}

Ion cross-sections can be determined from the IM drift times [59]:

$$
\Omega=\frac{(18 \pi)^{1 / 2}}{16} \frac{z e}{\left(k_{b} T\right)^{1 / 2}}\left[\frac{1}{m_{i}}+\frac{1}{m_{b}}\right]^{1 / 2} \frac{1}{N(0)} \frac{t_{D} E 760}{L} \frac{T}{P} \frac{T}{273.2}
$$

where $\mathrm{z}=$ ion charge $(+1,+2, \ldots), \mathrm{e}=$ charge on electron, $\mathrm{m}_{\mathrm{i}}=$ ion mass, $\mathrm{m}_{\mathrm{b}}=$ mass of the buffer gas particle, $\mathrm{E}=$ electric field through drift, $\mathrm{L}=$ length of the drift tube, $t_{D}=$ flight time through the drift tube, $\mathrm{N}(0)=$ gas number density at $\mathrm{STP}, \mathrm{P}, \mathrm{T}=$ pressure and temperature of the buffer gas.

The instrument provides the time between the ejection pulse from the IT and the start pulse of the TOF. For eqn 1 , the measured time $t_{D}$ should be only the time spent inside the drift tube. Therefore, the ion flight times between the drift tube and TOF source region (i.e., through the quadrupole and the ion lenses just to the left of it in Figure 1) are calculated from the lens dimensions and applied voltages and subtracted from the total time between IT and TOF extractor. The calculated times through the lenses and quadrupole range from $127 \mu \mathrm{s}$ for ubiquitin +8 to $360 \mu \mathrm{s}$ for ubiquitin +1 , i.e., the ions with the shortest and longest drift times. About $70 \%$ of this time is spent inside the quadrupole collision cell.

Many experimental parameters pertaining to the drift tube and ion funnel (e.g., axial electric field, injection pulser voltage, rf voltage on the ion funnel, etc.) were varied. Under the experimental conditions used in this work, none affected the numerical values of the measured cross sections, confirming that the ion mobility measurement is in the low field regime. Four parameters did influence the number of mobility peaks observed and their relative abundances: the voltage on the first electrode of the drift cell, the pressure in the drift cell, and the duration and magnitude of the voltage pulse used to eject ions from the IT. These effects are described below.

\section{Results and Discussion}

\section{IM-TOF MS after Ion/Ion Reactions}

In early research on proton transfer reactions with IM, a basic neutral gas was introduced into the source region to create lower charge state ions through an in-source proton transfer reaction [21,60]. In the present instrument, the total reaction time and reagent ion identity can be controlled. The experimental timing diagram (Figure 2) is similar to those previously shown for ion/ion reactions [38], except the usual IT mass analysis step is replaced by injection of product ions into the IM drift tube. The experiment scan function shown in 

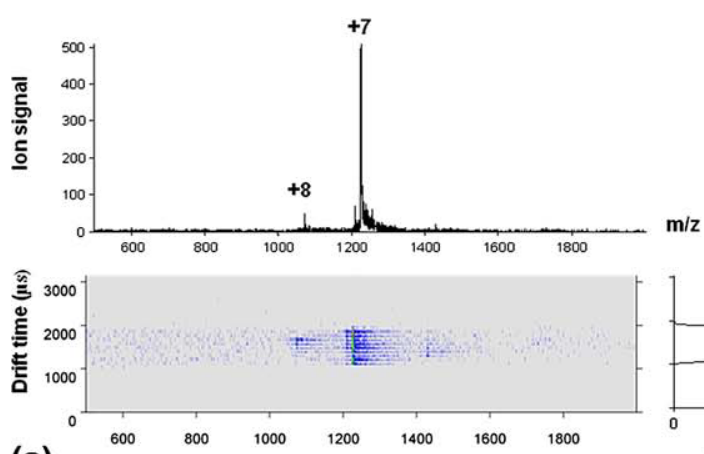

(a)
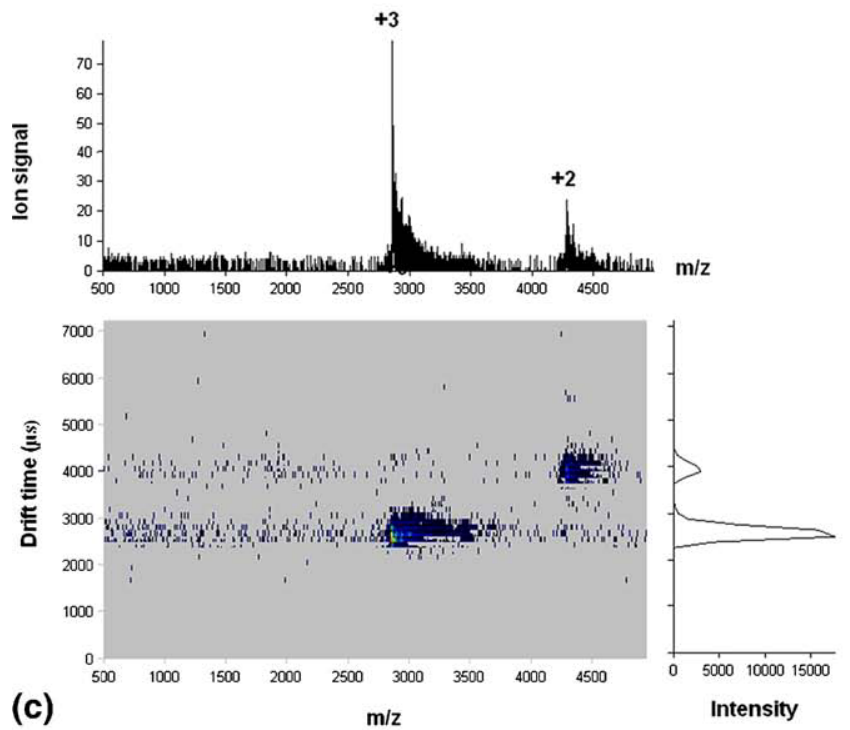
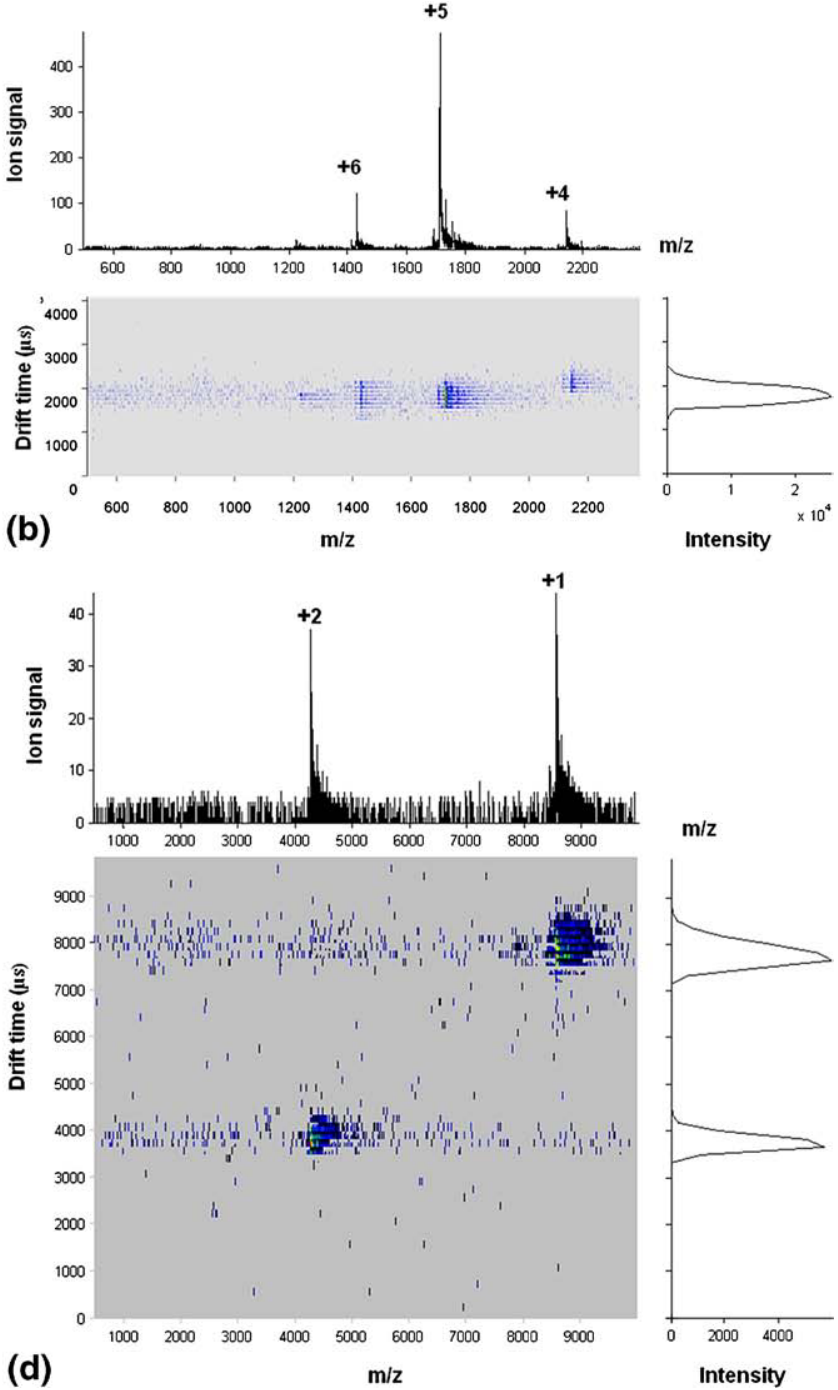

Intensity

Figure 3. (a) 3D mobility mass spectrum of ubiquitin; 3D mobility mass spectrum of ubiquitin after reaction with PDCH negative ions: (b) PDCH fill time $20 \mathrm{~ms}$, ion/ion reaction time $60 \mathrm{~ms}$; (c) PDCH fill time $45 \mathrm{~ms}$, ion/ion reaction time $150 \mathrm{~ms}$; (d) PDCH fill time $50 \mathrm{~ms}$, reaction time $180 \mathrm{~ms}$. The ions in lower charge states are more readily resolved by IM. Conditions: $0.30 \mathrm{mg} / \mathrm{mL}$ ubiquitin aqueous solution with $1 \%$ acetic acid, drift voltage $-30 \mathrm{~V}$ to $-580 \mathrm{~V}$, drift pressure $1.39 \mathrm{mbar}$, IT fill time for ubiquitin $50 \mathrm{~ms}$, data acquisition time: $10 \mathrm{~s}$ for (a), (b), (c), and $20 \mathrm{~s}$ for (d).

Figure 2 includes acquisition of nested drift (flight) time mobility data.

These capabilities are illustrated using charge reduction reactions of multiply charged ubiquitin ions with $\mathrm{PDCH}$ anions. The reagent anions are mainly $\left[\mathrm{M}-\mathrm{F}^{-}\right.$. and $\left[\mathrm{M}-\mathrm{CF}_{3}\right]^{-}$ions, as seen from a similar ASGDI source in another paper recently published from our group [61]. The signal ratio $[\mathrm{M}-\mathrm{F}]^{-} /\left[\mathrm{M}-\mathrm{CF}_{3}\right]^{-}$is $\sim 1.5$ in the present device.

For a typical ion/ion reaction-IM experiment, ubiquitin ions are injected for 50 to $100 \mathrm{~ms}, \mathrm{PDCH}^{-}$ions are injected for 5 to $50 \mathrm{~ms}$, and both polarity ions are trapped in the IT to react for 20 to $150 \mathrm{~ms}$, depending on the product ion charge states desired. An extraction pulse ( $-100 \mathrm{~V}$ for 3 to $10 \mu \mathrm{s})$ is then applied to the back end cap of the ion trap to inject ions into the drift tube.
For the IM separation the He pressure in the drift tube is $1.4 \mathrm{mbar}$, and the electric field applied is $12.4 \mathrm{~V} / \mathrm{cm}$ across the drift cell, with various injection voltages.

Figure 3a shows a 3D mobility- $\mathrm{m} / \mathrm{z}$ spectrum of ubiquitin before proton transfer reactions. The main charge state observed for ubiquitin under these solution and source conditions is +7 with a small but measurable amount of +8 . The mass resolution shown is $\mathrm{m} / \Delta \mathrm{m}=$ 1000 at $\mathrm{m} / \mathrm{z}$ 1224.6. Mass accuracies are within $28 \mathrm{ppm}$, using cytochrome $c+8$ and +9 ions as external calibrants.

Figure $3 b$, c, and d show spectra after ion/ion charge reduction reaction of ubiquitin with $\mathrm{PDCH}^{-}$. Ubiquitin +8 and +7 ions are converted to lower charge states than those produced directly by ESI, using longer fill and reaction times. The ions in lower charge states are better resolved in the IM dimension, probably because 
(1) fewer conformations are available at lower charge state, and/or (2) at lower charge states the conformations are more folded and have more uniform cross sections.

Previous attempts at analysis of protein mixtures by CID after IM separation suffered because protein ions in high charge states were not resolved in the mobility separation [62]. Thus, mobility labeling for proteins is not as useful as for peptides. Ion/ion reaction combined with IM separations provides a new technique to improve the performance of mobility labeling (for on-thefly MS/MS) for top-down analysis of intact proteins.

The various drift time versus $m / z$ plots in Figure 3 show dense "bunches" of ions at the expected $\mathrm{m} / \mathrm{z}$ values and diffuse "streaks" at all $\mathrm{m} / \mathrm{z}$ values. These streaks have the same drift time as the expected ions; this is especially evident in Figure $3 c$ and $d$ for the ions in low charge states. Thus, it is believed that this background is caused by protein ions that get into the TOF region at times other than the TOF extraction pulse.

\section{Cross-Section Measurements}

Observed values for ubiquitin ions using three injection voltages are depicted in Figure 4. Numerical cross section values from the plots in Figure 4 are listed in Table 1, and conditions and scale values are given in Table 2. IM spectra and the resulting cross sections obtained at higher injection voltages do not differ appreciably from those measured at $-50 \mathrm{~V}$ and are not shown.

First, consider the +8 and +7 ions, which come directly from the ESI source. The +8 ions are unfolded at all injection voltages, while the +7 ions are observed in up to three IM peaks, as noted above. The +6 to +1 ions come from proton transfer reaction, mainly with the +7 ubiquitin ions originally present. Reducing the charge state converts the ubiquitin ions to more compact conformers. For ions in the lower charge states, the single IM peak gets narrower as charge state is reduced. For ubiquitin +1 , the FWHM of the ion mobility peak $(\sim 500 \mu \mathrm{s})$ is still a factor of three wider than the FWHM $\mathbf{0 V}$

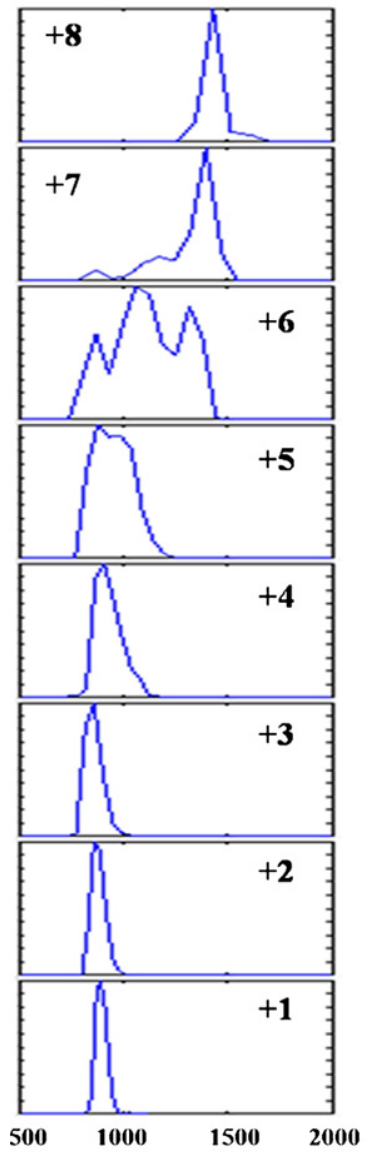

$-30 \mathrm{~V}$

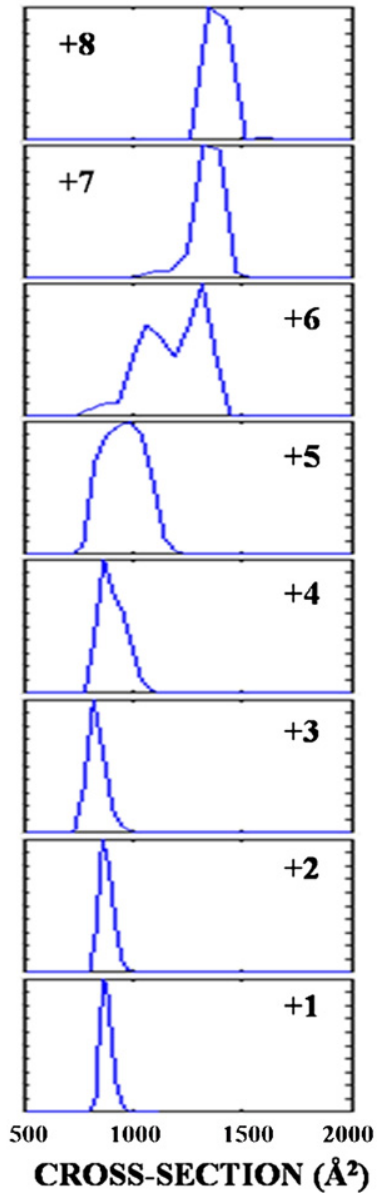

$-\mathbf{5 0 V}$

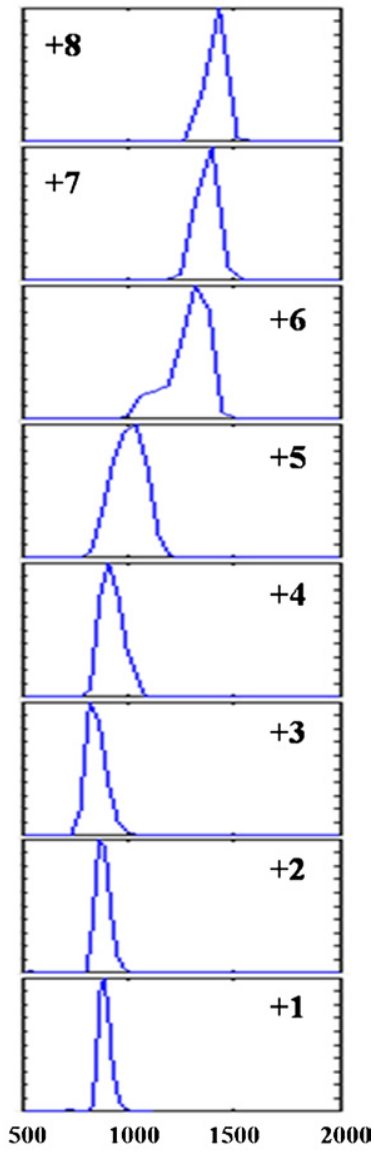

Figure 4. Cross section distributions for ubiquitin ions in various charge states. +8 and +7 ions are made from nano-ESI of $0.30 \mathrm{mg} / \mathrm{mL}$ ubiquitin aqueous solution with $1 \%$ acetic acid. The other ions are made by ion/ion reaction with PDCH anions under the conditions described in Table 2. Vertical scale values are also given in Table 2. Numerical values for cross section are listed in Table 1 . The injection voltages are $0,-30 \mathrm{~V}$, or $-50 \mathrm{~V}$, as indicated. The IT ejection pulse is $-100 \mathrm{~V}$ for $5 \mu \mathrm{s}$, and the axial electric field through the drift tube is $12.4 \mathrm{~V} / \mathrm{cm}$. 
Table 1. Measured cross-sections for ubiquitin ions in different charge states; +7 and +8 ions are from the ESI source, ions with charge states +6 to +1 are made from mostly +7 ions by ion/ion reaction

\begin{tabular}{ccccc}
\hline \multirow{2}{*}{$\begin{array}{c}\text { Charge } \\
\text { state }\end{array}$} & \multicolumn{4}{c}{ Cross-section $\left(\AA^{2}\right)$ at indicated injection voltage } \\
\cline { 2 - 5 } & $0 \mathrm{~V}$ & $-30 \mathrm{~V}$ & $-50 \mathrm{~V}$ & $-100 \mathrm{~V}$ \\
\hline \hline+8 & 1428 & 1430 & 1430 & 1428 \\
+7 & 1393 & 1394 & 1394 & 1393 \\
+6 & $863,1056,1314$ & $863,1056,1314$ & 1314 & 1312 \\
+5 & 872,979 & 979 & 1033 & 1031 \\
+4 & 904 & 861 & 904 & 902 \\
+3 & 855 & 813 & 814 & 814 \\
+2 & 854 & 856 & 857 & 857 \\
+1 & 882 & 861 & 882 & 861 \\
\hline
\end{tabular}

See text for conditions. The cross-sections are determined from the apex of the various mobility peaks (Figure 5) according to eq 1 . Uncertainties are estimated to be approximately $\pm 50 \AA^{2}$ based on many repeated measurements over several months.

of the diffusion limited peak $(\sim 175 \mu \mathrm{s}$, calculated as described in the literature) [63-65]. Thus, we suggest that the single IM peaks for ubiquitin in low charge states are comprised of contributions from several unresolved conformers [49], and fewer such conformers are present at lower charge states.

Numerical data for cross sections are given in Table 1. Multiple entries indicate values from several discernable peaks in the IM spectra (Figure 4). The ions in low charge states have essentially a single value of cross section corresponding to folded conformer(s) of ubiquitin, even though the original ubiquitin +7 ions have a variety of conformations before the ion/ion reaction. In general, the measured cross-sections of +8 to +4 ubiquitin ions are in the range of the literature values [21]. This is the first report of cross-sections for ubiquitin +3 , +2 , and +1 ions.

Table 2. Reaction conditions and vertical scale values for cross-section plots in Figure 5. Other conditions: ubiquitin fill time $50 \mathrm{~ms}$, extraction pulse from ion trap $-100 \mathrm{~V}$ for $5 \mu \mathrm{s}$ except for +1 ions, which were pulsed out for $10 \mu \mathrm{s}$ at $-150 \mathrm{~V}$

\begin{tabular}{|c|c|c|c|c|c|}
\hline \multirow{4}{*}{$\begin{array}{c}\text { Charge } \\
\text { state }\end{array}$} & \multirow{3}{*}{\multicolumn{2}{|c|}{$\frac{\text { Time values }(\mathrm{ms})}{\mathrm{PDCH}}$}} & \multirow{3}{*}{\multicolumn{3}{|c|}{$\begin{array}{c}\text { Full-scale signal (counts/s) } \\
\begin{array}{c}\text { At indicated injection } \\
\text { voltage }\end{array}\end{array}$}} \\
\hline & & & & & \\
\hline & & & & & \\
\hline & Fill & Reaction & $0 \mathrm{~V}$ & $-30 \mathrm{~V}$ & $-50 \mathrm{~V}$ \\
\hline$+8^{*}$ & & $60^{*}$ & 38 & 137 & 83 \\
\hline$+7^{*}$ & & $60^{*}$ & 189 & 546 & 380 \\
\hline+6 & 20 & 60 & 33 & 154 & 116 \\
\hline+5 & 20 & 60 & 136 & 522 & 373 \\
\hline+4 & 20 & 60 & 26 & 191 & 81 \\
\hline+3 & 45 & 150 & 258 & 642 & 873 \\
\hline+2 & 45 & 150 & 350 & 182 & 114 \\
\hline+1 & 50 & 180 & 18 & 320 & 159 \\
\hline
\end{tabular}

*These ions were observed directly from the ESI source without ion/ion reaction. To keep the total trapping time constant without inducing ion/ion reactions, the ASGDI source was turned off while these ions were measured.
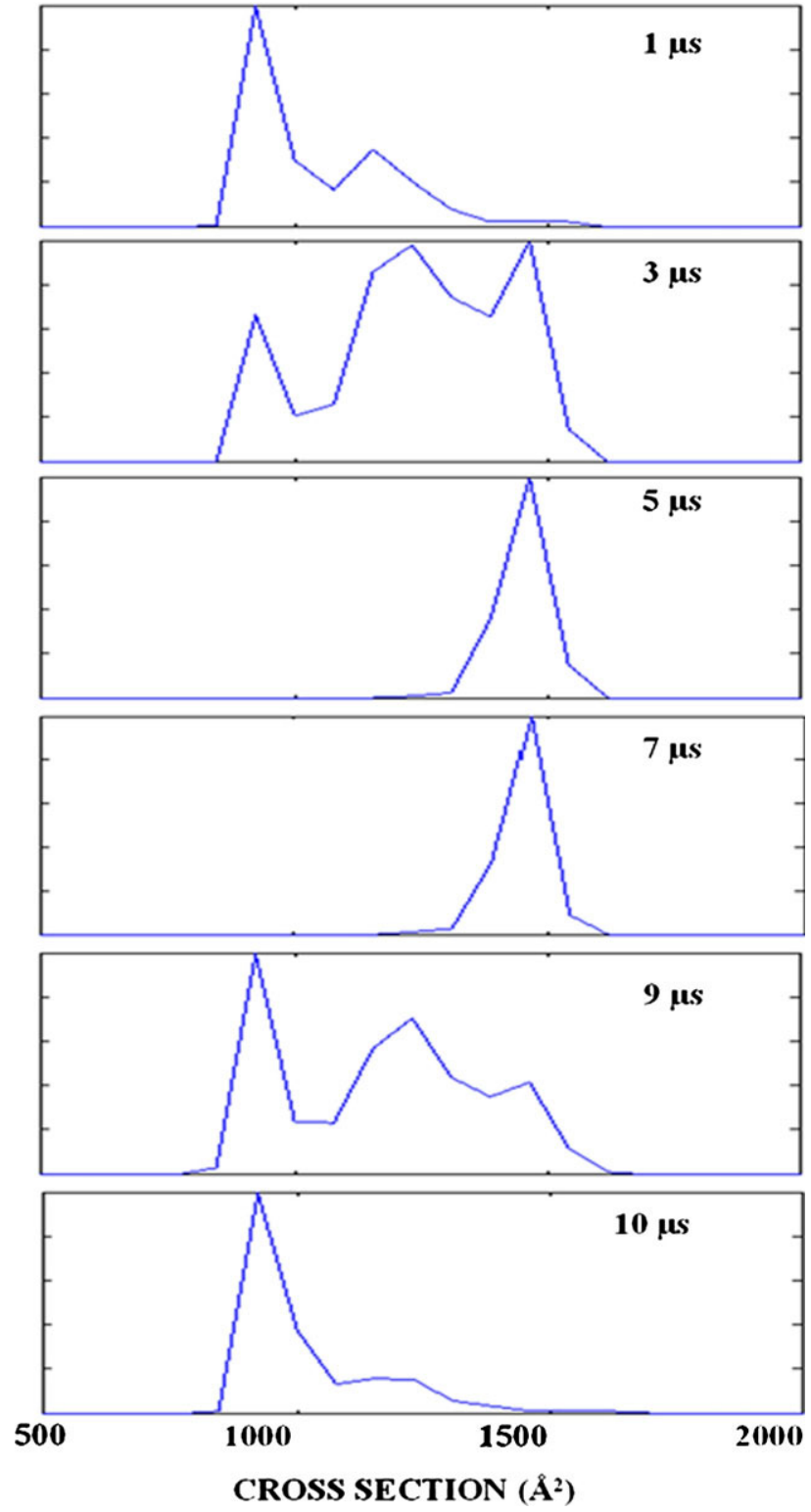

Figure 5. Effect of duration of IT ejection pulse on conformations of ubiquitin +7 ions directly from ESI source, without ion/ion reaction. IT ejection voltage: $-100 \mathrm{~V}$, IM injection voltage: $-30 \mathrm{~V}$.

Most of the numerical cross section values in Table 1 do not vary much with injection voltage. For the $5+$ ions, the cross section shown in the table does appear to change, but examination of Figure 4 shows that this is mainly due to changes in peak structure and width from various conformers induced by the changes in injection voltage.

This device also provides reasonable IM spectra for ions injected at very low kinetic energy, although the transmission and sensitivity are naturally lower at very low injection voltage. Apparently, some ions in the trap are moving toward the drift tube before the negative injection pulse is applied to the endcap. Otherwise ions could not enter the higher-pressure drift tube ( $\sim 1$ mbar $)$ at a nominal injection voltage of zero. 


\section{Effects of Drift Tube Injection Conditions on Folding of Ubiquitin Ions}

Clemmer's group [21] studied how injection energy influences mobility spectra of ubiquitin ions and the apparent number and relative abundance of protein conformers. At low injection energy $(385 \mathrm{eV}$, or $55 \mathrm{~V}$ for ubiquitin +7), different conformers were observed and the distributions were expected to reflect the distribution of conformers from the ion source [21].

Similar effects were seen in the present work for ubiquitin ions in certain charge states, as shown in Figure 4, which includes results at lower injection voltages (i.e. $0 \mathrm{~V}$ ) than those reported by Clemmer. The relative abundances of various peaks in the IM spectra do not change further as injection voltage is raised above $50 \mathrm{~V}$ (data from -60 to $-150 \mathrm{~V}$ are not shown). Briefly, Figure 4 shows that +8 ions remain unfolded, and +5 to +1 ions remain folded, regardless of injection voltage. For the intermediate charge states +6 and +7 , lower injection voltage generally favors formation of more folded conformers. More open conformers for the +6 and +7 ions are also less abundant at lower pressure inside the drift tube (data not shown).

In general, these observations are consistent with ions being heated and unfolded initially by collisions in the short space $(1.3 \mathrm{~cm})$ between the trap exit and drift tube. Ions in intermediate charge states have various folded states accessible and may refold when further collisions cool the ions, either during extraction or inside the drift tube. Differential scattering of larger ions outside the acceptance of the small entrance aperture ( $0.5 \mathrm{~mm}$ diam.) of the drift tube may also contribute to these observations.

The duration and magnitude of the negative voltage pulse applied to eject ions from the IT can also affect the number of peaks in the IM spectra for the +7 ions, i.e., those ions that are prone to folding changes. Such effects are most pronounced if the ejection pulse is more negative than the voltage on the entrance to the drift tube. Figure 5 depicts an extreme example; the ejection pulse amplitude is $-100 \mathrm{~V}$, and the drift tube entrance is at $-30 \mathrm{~V}$. Ubiquitin +7 ions are mostly folded using the shortest ejection pulse $(1 \mu \mathrm{s})$. A variety of conformers are seen at $3 \mu \mathrm{s}$, while the ions are unfolded when the ejection pulse lasts for 5 or $7 \mu \mathrm{s}$. Curiously, the ions are folded if the ejection pulse is extended further to 9 or $10 \mu \mathrm{s}$. The drift time changes corresponding to the various cross sections shown in Figure 5 are substantial $(\sim 100 \mu \mathrm{s})$, much longer than even the longest injection times, so the observed cross section changes are attributed to real changes in protein conformation, not just differences in injection time.

We have not found descriptions of effects quite like those shown in Figure 5 in previous literature involving injection of ions into IM drift tubes. A long ion ejection pulse is of use mainly because it improves signals for ions in low charge states, as if $\sim 10 \mu$ s are required to draw the less highly charged ions out of the trap.
Fortunately, the ions in low charge states remain folded anyway, and a long extraction pulse is generally not needed to obtain adequate sensitivity for the ions in the intermediate charge states that are more susceptible to folding changes. Use of an extraction pulse that is less negative than the entrance to the drift tube also reduces the magnitude of these folding changes.

Varying the injection voltage and duration of the ion ejection pulse also induces similar changes in conformations of cytochrome $c$, especially the +7 and +8 ions [66]. We offer the following tentative, qualitative explanation for these observations. It seems like the location of the ions, when the pulse polarity changes, is important. Consider the plots in Figure 5 with an ejection pulse amplitude of $-100 \mathrm{~V}$ for various times. An ubiquitin $7+$ ion at rest in the center of the trap would take $3.6 \mu \mathrm{s}$ to travel the $0.707 \mathrm{~cm}$ to the trap exit. Some ions are moving toward the trap exit and get there sooner, others take longer. For short ejection pulses (1 $\mu \mathrm{s})$, the ejected ions have not gone far past the trap when the ejection pulse goes back to zero. If the trap exit remains at $-100 \mathrm{~V}$ long enough, the ions go through this $1.3 \mathrm{~cm}$ long region and are all inside the drift tube before the trap exit voltage changes. At -100 $\mathrm{V}$ this transit is estimated to take $4.2 \mu \mathrm{s}$, for a total time of $\sim 8 \mu \mathrm{s}$. The longest ejection pulse used $(10 \mu \mathrm{s})$ exceeds this transit time, so the trap exit remains at a constant voltage $(-100 \mathrm{~V})$ until all the ions are inside the drift tube. Thus at either short $(1 \mu \mathrm{s})$ or long $(10 \mu \mathrm{s})$ ejection times, most of the ions remain folded, and the mobility spectra in these two cases are similar.

With $-100 \mathrm{~V}$ ejection pulses for times between $3 \mu \mathrm{s}$ and $9 \mu \mathrm{s}$, many of the ions are between the trap exit and the drift tube entrance when the voltage on the trap exit returns to zero. As the ejection pulse duration increases from 3 to 5 to $7 \mu \mathrm{s}$, the ions are expected to be closer to the drift tube entrance, where the density of He gas escaping from the drift tube is higher than it is closer to the trap exit. This voltage change and the accompanying collisions with gas induce the observed folding changes. For $5 \mu \mathrm{s}$ and $7 \mu \mathrm{s}$, the ions are mostly unfolded. The unfolding effects are more extensive at times where the bulk of the ions are still between the ion trap exit and drift tube entrance when the voltage on the trap exit returns to zero.

At an ejection time of $9 \mu \mathrm{s}$, some of the ejected ions are already inside the drift tube when the voltage on the trap exit changes, so some ions are not affected by the voltage change. The resulting mobility spectrum shows ions in a range of conformations, like that observed at 3 $\mu \mathrm{s}$. There are still collisions with gas for either short or long ejection pulses; apparently these collisions are most effective at changing the conformations of the ions if the ions are closer to, but not inside the drift tube when the trap exit voltage changes.

Badman et al. [67] and Myung et al. [48] observed that the folding and unfolding of cytochrome $c$ and ubiquitin ions in intermediate charge states occurred while ions were stored for $\sim 100 \mathrm{~ms}$ in a 3D ion trap. In 

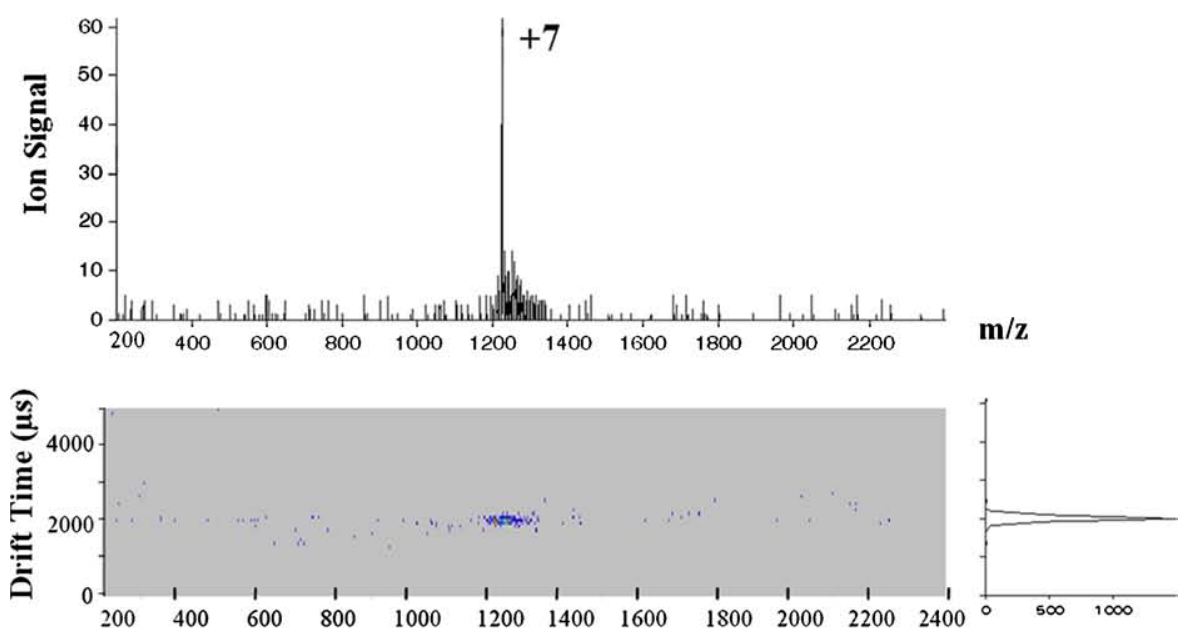

(a)

$\mathbf{m} / \mathbf{z}$

Ion Signal
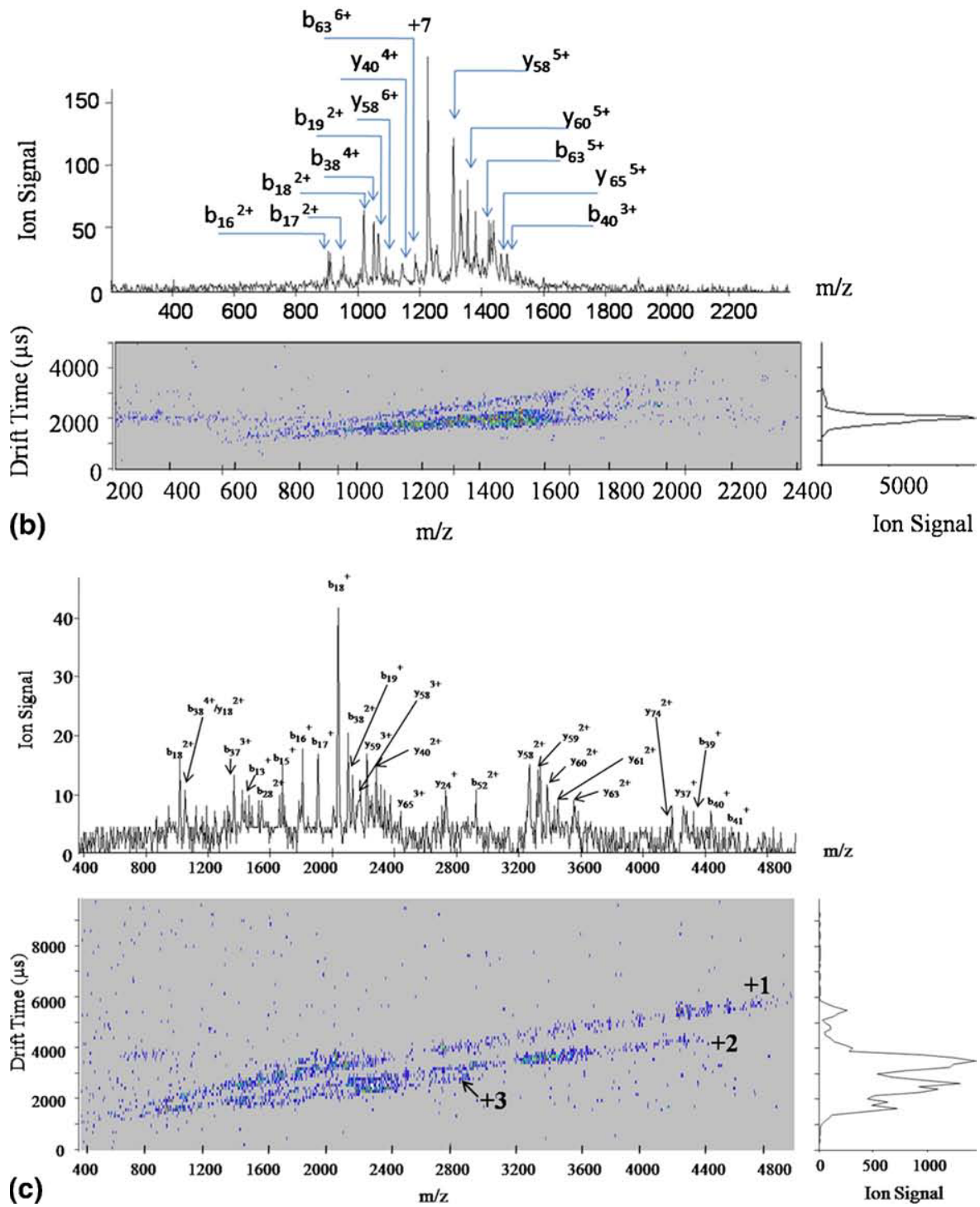

Figure 6. CID results: (a) 3D ion mobility spectrum of ubiquitin +7 ions isolated in 3D IT; (b) fragments directly from CID of ubiquitin +7 ions in IT; (c) charge reduced CID fragments from ubiquitin +7 ions after reaction with PDCH anions for $100 \mathrm{~ms}$. 
the present work, changing the duration of the extraction pulse from 1 to $10 \mu$ s can also affect the observed conformations, so some folding and unfolding events apparently can occur on the microsecond time scale.

The underlying causes of the changes reported here could be related to recent work by Shvartsburg et al. [52], who studied conformation changes in ubiquitin ions during field asymmetric waveform ion mobility spectrometry (FAIMS). They attribute such conformation changes to heating induced repetitively during the high voltage segments of the FAIMS waveform. Each high voltage segment lasts $\sim 0.1 \mu \mathrm{s}$; during many FAIMS cycles, the cumulative conformation changes induced on ubiquitin ions in intermediate charge states (especially +7 ) as a result of many such excitation/ heating events are substantial.

The charge states where folding changes are expected probably vary between proteins, so these effects should be evaluated on a case-by case basis. So far, ions in the higher and lower charge states are less prone to these folding changes. Even for these charge states, there may still be subtle changes in the distributions of closely-related conformers hidden by the relatively low IM resolution in our experiments, compared to the much narrower peaks seen in Clemmer's tandem IM work [68, 69].

\section{CID on Intact Proteins followed by Charge Reduction}

This instrument also has potential value for top-down proteomics measurements, as indicated by the following example. Figure 6a shows a spectrum obtained after isolating only the +7 charge state of ubiquitin in the ion trap. Mass selection was performed by applying first a $30 \mathrm{kHz} 12 \mathrm{~V}_{p-p}$ AC waveform to the entrance endcap of the ion trap to resonantly eject lower mass ions during an RF ramp. Then a $20 \mathrm{kHz} 10 \mathrm{~V}_{p-p}$ AC waveform ejected higher mass ions during another RF ramp [38]. The IM peak in Figure 6a is narrower than that in Figure 3 because a higher injection voltage $(-150 \mathrm{~V})$ was used for Figure 6a.

In a subsequent experiment, ubiquitin +7 ions were stored in the ion trap for $20 \mathrm{~ms}$ and activated for $100 \mathrm{~ms}$ at $50 \mathrm{kHz}, 23 \mathrm{~V}_{p-p}$. The fragment spectrum (Figure 6b) shows CID product ions in a variety of relatively high charge states that are only moderately resolved in the IM dimension. Thus, it is not easy to assign them at first.

Figure $6 \mathrm{c}$ shows the spectrum resulting from charge reduction of the fragment ions in the ion trap with $\mathrm{PDCH}$ anions (injection for $20 \mathrm{~ms}$, reaction for $100 \mathrm{~ms}$ ). The spectrum shifts to higher $m / z$, and the dispersion in the IM dimension is greatly improved. Many of the charge-reduced CID fragments can now be assigned by comparing the observed $\mathrm{m} / \mathrm{z}$ values with those of fragments generated from the known sequence of ubiquitin. The mass tolerance for these assignments is $\pm 0.6 \mathrm{Th}$. The assumption that the fragment ions in Figure $6 \mathrm{c}$ are in low charge states greatly simplifies these assignments. Most of the fragments observed here are $b$ and $y$ ions; $b_{18}$ and $y_{58}$ are abundant fragments, in agreement with other studies [38, 70].

The IM plot for the charge-reduced fragments (Figure 6c) shows distinct groups that fall along slanted lines of different slopes for peptide fragment ions in +1 , +2 , and +3 charge states, as noted by Clemmer and coworkers. This phenomenon provides additional evidence to help assign charge states. These groups merge closer together at higher charge states [17], which is one reason they are poorly resolved in Figure $6 \mathrm{~b}$.

Armed with the identities of the charge-reduced fragments (Figure 6c), many of the original, more highly charged fragments in Figure $6 \mathrm{~b}$ can now be assigned. For example, $\mathrm{y}_{58}{ }^{2+}$ is in the charge-reduced spectrum. Thus, a more highly charged version $\left(\mathrm{y}_{58}{ }^{5+}\right.$ in this case) should appear in the original CID spectrum (Figure 6b), along with the complementary $b_{18}{ }^{2+}$ ions. Note that the charge states of these two fragments add up to the original +7 , as expected. Here we assume that the peptide fragment ions do not dissociate further during the charge reduction reactions, as shown by McLuckey [31]. A number of other, similar cases are identified in Figure 6.

\section{Conclusion}

This is the first instrument that combines ion/ion reactions and IM separations with full computer control of all functions. It should prove useful for study of the effects of protein charge state on conformation, which is key to the general question of the relation between gas-phase conformation and that in solution [71-73]. Protein ions in solution generally have lower net charges than those observed in the gas-phase after ESI; this methodology provides a way to access ions in these physiologically relevant charge states. Other types of ion/ion reactions, such as ETD, formation of proteinmetal, protein-ligand, and protein-protein complexes, should also be possible, with the added benefit of the ability to also manipulate charge state. Finally, manipulation of charge state of CID products facilitates high throughput top-down protein analysis. A number of improvements in the instrumentation, such as use of a linear ion trap instead of the 3D ion trap, CID at higher energy, CID of mobility-selected ions using the quadrupole collision cell, and multiple reflections in the TOFMS for higher resolution, are under investigation in our laboratory. Also, a more detailed study of conformation changes in the $\mu$ s time scale between the ion trap and the drift tube may prove interesting in its own right.

\section{Acknowledgments}

The authors acknowledge helpful discussions with Steve Valentine (Indiana University); Scott McLuckey for the design of highvoltage switches; Brent Knecht, Garth Patterson, Brent Rardin, and 
Mitch Wells (Griffin Analytical) for assistance with the Argos and software; David Prior (Pacific Northwest National Lab) for design of the IT rf amplifier; and Randy Pedder (Ardara Technologies, North Huntingdon, PA) for advice on use of the rf supply for the ion funnel. Other custom electronics were designed and constructed by Lee Harker (Ames Lab Engineering Services Group); vacuum welding by Charlie Burg (Ames Lab); precision machining by Richard Egger, the late Steve Lee, and Terry Soseman (ISU Chemistry Machine Shop). Derrick Morast analyzed the ubiquitin sample with another ESI instrument to evaluate its purity. ERB acknowledges funding from Waters Corp. via an ASMS Research Award. The authors gratefully acknowledge funding from Iowa State University: College of Liberal Arts and Sciences, Office of Biotechnology, Plant Sciences Institute, and the Carver Trust.

\section{Appendix A Supplementary Material}

Supplementary material associated with this article may be found in the online version at doi:10.1016/ j.jasms.2009.04.014.

\section{References}

1. Pandey, A.; Mann, M. Proteomics to Study Genes and Genomes. Nature 2000, 405, 837-846.

2. Sobott, F.; McCammon, M. G.; Hernandez, H.; Robinson, C. V. The Flight of Macromolecular Complexes in a Mass Spectrometer. Philos. Trans. R. Soc. Lond. Ser. A Math. Phys. Eng. Sci. 2005, 363, 379-389.

3. Loo, J. A.; Berhane, B.; Kaddis, C. S.; Wooding, K. M.; Xie, Y. M.; Kaufman, S. L.; Chernushevich, I. V. Electrospray Ionization Mass Spectrometry and Ion Mobility Analysis of the 20s Proteasome Complex. J. Am. Soc. Mass Spectrom. 2005, 16, 998-1008.

4. St. Louis, R. H.; Hill, H. H. Ion Mobility Spectrometry in Analytical Chemistry. Crit. Rev. Anal. Chem. 1990, 21, 321-355.

5. Collins, D. C.; Lee, M. L. Developments in Ion Mobility SpectrometryMass Spectrometry. Anal. Bioanal. Chem. 2002, 372, 66-73.

6. Bohrer, B. C.; Merenbloom, S. I.; Koeniger, S. L.; Hilderbrand, A. E.; Clemmer, D. E. Biomolecule Analysis by Ion Mobility Spectrometry. Annu. Rev. Anal. Chem. 2008, 1, 293-327.

7. Jarrold, M. F. Peptides and Proteins in the Vapor Phase. Annu. Rev. Phys. Chem. 2000, 51, 179-207.

8. Hoaglund, C. S.; Valentine, S. J.; Sporleder, C. R.; Reilly, J. P.; Clemmer, D. E. Three-Dimensional Ion Mobility TOK MS Analysis of Electrosprayed Biomolecules. Anal. Chem. 1998, 70, 2236-2242.

9. Smith, D. P.; Giles, K.; Bateman, R. H.; Radford, S. E.; Ashcroft, A. E. Monitoring Copopulated Conformational States During Protein Folding Events Using Electrospray Ionization-Ion Mobility Spectrometry-Mass Spectrometry. J. Am. Soc. Mass Spectrom. 2007, 18, 2180-2190.

10. Steiner, W. E.; Clowers, B. H.; English, W. A.; Hill, H. H. Atmospheric Pressure Matrix-Assisted Laser Desorption/Ionization with Analysis by Ion Mobility Time-of-Flight Mass Spectrometry. Rapid Commun. Mass Spectrom. 2004, 18, 882-888.

11. Steiner, W. E.; Clowers, B. H.; Fuhrer, K.; Gonin, M.; Matz, L. M.; Siems, W. F.; Schultz, A. J.; Hill, H. H. Electrospray Ionization with Ambient Pressure Ion Mobility Separation and Mass Analysis by Orthogonal Time-of-Flight Mass Spectrometry. Rapid Commun. Mass Spectrom. 2001, 15, 2221-2226

12. Stone, E.; Gillig, K. J.; Ruotolo, B.; Fuhrer, K.; Gonin, M.; Schultz, A.; Russell, D. H. Surface-Induced Dissociation on a MALDI -Ion MobilityOrthogonal Time-of-Flight Mass Spectrometer: Sequencing Peptides from an "in-Solution" Protein Digest. Anal. Chem. 2001, 73, 2233-2238.

13. Stone, E. G.; Gillig, K. J.; Ruotolo, B. T.; Russell, D. H. Optimization of a Matrix-Assisted Laser Desorption Ionization-Ion Mobility-SurfaceInduced Dissociation-Orthogonal-Time-of-Flight Mass Spectrometer: Simultaneous Acquisition of Multiple Correlated MS1 and MS2 Spectra. Int. J. Mass Spectrom. 2001, 212, 519-533.

14. Hoaglund-Hyzer, C. S.; Li, J. W.; Clemmer, D. E. Mobility Labeling for Parallel CID of Ion Mixtures. Anal. Chem. 2000, 72, 2737-2740.

15. Hoaglund-Hyzer, C. S.; Clemmer, D. E. Ion Trap/Ion Mobility/ Quadrupole/Time of Flight Mass Spectrometry for Peptide Mixture Analysis. Anal. Chem. 2001, 73, 177-184.

16. Henderson, S. C.; Valentine, S. J.; Counterman, A. E.; Clemmer, D. E. ESI/Ion Trap/Ion Mobility/Time-of-Flight Mass Spectrometry for Rapid and Sensitive Analysis of Biomolecular Mixtures. Anal. Chem. 1999, 71, 291-301.

17. Myung, S.; Lee, Y. J.; Moon, M. H.; Taraszka, J.; Sowell, R.; Koeniger, S.; Hilderbrand, A. E.; Valentine, S. J.; Cherbas, L.; Cherbas, P.; Kaufmann, T. C.; Miller, D. F.; Mechref, Y.; Novotny, M. V.; Ewing, M. A.; Sporleder, C. R.; Clemmer, D. E. Development of High-Sensitivity Ion
Trap Ion Mobility Spectrometry Time-of-Flight Techniques: A High-Throughput Nano-LC-IMS-TOF Separation of Peptides Arising from a Drosophila Protein Extract. Anal. Chem. 2003, 75, 5137-5145.

18. Badman, E. R.; Myung, S.; Clemmer, D. E. Gas-Phase Separations of Protein and Peptide Ion Fragments Generated by Collision-Induced Dissociation in an Ion Trap. Anal. Chem. 2002, 74, 4889-4894.

19. Green, M. K.; Lebrilla, C. B. Ion-Molecule Reactions as Probes of Gas-Phase Structures of Peptides and Proteins. Mass Spectrom. Rev. 1997, $16,53-71$.

20. Valentine, S. J.; Anderson, J. G.; Ellington, A. D.; Clemmer, D. E. Disulfide-Intact and -Reduced Lysozyme in the Gas Phase: Conformations and Pathways of Folding and Unfolding. J. Phys. Chem. B 1997, 101, 3891-3900.

21. Valentine, S. J.; Counterman, A. E.; Clemmer, D. E. Conformer-Dependent Proton-Transfer Reactions of Ubiquitin Ions. J. Am. Soc. Mass Spectrom. 1997, 8, 954-961.

22. Valentine, S. J.; Clemmer, D. E. H. /D Exchange Levels of ShapeResolved Cytochrome $c$ Conformers in the Gas Phase. J. Am. Chem. Soc. 1997, 119, 3558-3566.

23. Woenckhaus, J. Drift Time Mass Spectrometric Protein Hydration Experiments. Int. J. Mass Spectrom. 2002, 213, 9-24.

24. Woenckhaus, J.; Mao, Y.; Jarrold, M. F. Hydration of Gas Phase Proteins: Folded +5 and Unfolded +7 Charge States of Cytochrome c. J. Phys. Chem. B 1997, 101, 847-851.

25. Fye, J. L.; Woenckhaus, J.; Jarrold, M. F. Hydration of Folded and Unfolded Gas-Phase Proteins: Saturation of Cytochrome $c$ and Apomyoglobin. J. Am. Chem. Soc. 1998, 120, 1327-1328.

26. Wyttenbach, T.; Liu, D. F.; Bowers, M. T. Hydration of Small Peptides Int. J. Mass Spectrom. 2005, 240, 221-232.

27. Loo, R. R. O.; Udseth, H. R.; Smith, R. D. A New Approach for the Study of Gas-Phase Ion-Ion Reactions Using Electrospray Ionization. J. Am. Soc. Mass Spectrom. 1992, 3, 695-705.

28. Loo, R. R. O.; Udseth, H. R.; Smith, R. D. Evidence of Charge Inversion in the Reaction of Singly Charged Anions with Multiply Charged Macroions. J. Phys. Chem. 1991, 95, 6412-6415.

29. Pitteri, S. J.; McLuckey, S. A. Recent Developments in the Ion/Ion Chemistry of High-Mass Multiply Charged Ions. Mass Spectrom. Rev. 2005, 24, 931-958.

30. Stephenson, J. L.; McLuckey, S. A. Ion/Ion Proton Transfer Reactions for Protein Mixture Analysis. Anal. Chem. 1996, 68, 4026-4032.

31. Stephenson, J. L.; McLuckey, S. A. Simplification of Product Ion Spectra Derived from Multiply Charged Parent Ions Via Ion/Ion Chemistry. Anal. Chem. 1998, 70, 3533-3544.

32. McLuckey, S. A.; Reid, G. E.; Wells, J. M. Ion Parking During Ion/Ion Reactions in Electrodynamic Ion Traps. Anal. Chem. 2002, 74, 336-346.

33. Syka, J. E. P.; Coon, J. J.; Schroeder, M. J.; Shabanowitz, J.; Hunt, D. F. Peptide and Protein Sequence Analysis by Electron Transfer Dissociation Mass Spectrometry. Proc. Natl. Acad. Sci. U.S.A. 2004, 101, 95289533.

34. Stephenson, J. L.; McLuckey, S. A. Adaptation of the Paul Trap for Study of the Reaction of Multiply Charged Cations with Singly Charged Anions. Int. J. Mass Spectrom. Ion. Processes 1997, 162, 89-106.

35. Reid, G. E.; Wells, J. M.; Badman, E. R.; McLuckey, S. A. Performance of a Quadrupole Ion Trap Mass Spectrometer Adapted for Ion/Ion Reaction Studies. Int. J. Mass Spectrom. 2003, 222, 243-258.

36. Wu, J.; Hager, J. W.; Xia, Y.; Londry, F. A.; McLuckey, S. A. Positive Ion Transmission Mode Ion/Ion Reactions in a Hybrid Linear Ion Trap. Anal. Chem. 2004, 76, 5006-5015.

37. Xia, Y.; Liang, X. R.; McLuckey, S. A. Pulsed Dual Electrospray Ionization for Ion/Ion Reactions. J. Am. Soc. Mass Spectrom. 2005, 16 , 1750-1756.

38. Badman, E. R.; Chrisman, P. A.; McLuckey, S. A. A Quadrupole Ion Trap Mass Spectrometer with Three Independent Ion Sources for the Study of Gas-Phase Ion/Ion Reactions. Anal. Chem. 2002, 74, 6237-6243.

39. Liang, X. R.; Xia, Y.; McLuckey, S. A. Alternately Pulsed Nanoelectrospray Ionization/Atmospheric Pressure Chemical Ionization for Ion/ Ion Reactions in an Electrodynamic Ion Trap. Anal. Chem. 2006, 78 , 3208-3212.

40. Liang, X. R.; Han, H. L.; Xia, Y.; McLuckey, S. A. A Pulsed Triple Ionization Source for Sequential Ion/Ion Reactions in an Electrodynamic Ion Trap. J. Am. Soc. Mass Spectrom. 2007, 18, 369-376.

41. Pitteri, S. J.; Chrisman, P. A.; Hogan, J. M.; McLuckey, S. A. Electron Transfer Ion/Ion Reactions in a Three-Dimensional Quadrupole Ion Trap: Reactions of Doubly and Triply Protonated Peptides with $\mathrm{SO}_{2}-$ Anal. Chem. 2005, 77, 1831-1839.

42. Chrisman, P. A.; Pitteri, S. J.; Hogan, J. M.; McLuckey, S. A. $2^{-}$. Electron Transfer Ion/Ion Reactions with Disulfide Linked Polypeptide Ions. J. Am. Soc. Mass Spectrom. 2005, 16, 1020-1030.

43. Han, H.; Xia, Y.; Yang, M.; McLuckey, S. A. Rapidly Alternating Transmission Mode Electron-Transfer Dissociation and Collisional Activation for the Characterization of Polypeptide Ions. Anal. Chem. 2008, $80,3492-3497$.

44. Xia, Y.; Han, H.; McLuckey, S. A. Activation of Intact Electron-Transfer Products of Polypeptides and Proteins in Cation Transmission Mode Ion/Ion Reactions. Anal. Chem. 2008, 80, 1111-1117.

45. Phanstiel, D.; Zhang, Y.; Marto, J. A.; Coon, J. J. Peptide and Protein Quantification Using ITRAQ with Electron Transfer Dissociation. J. Am. Soc. Mass Spectrom. 2008, 19, 1255-1262. 
46. McAlister, G. C.; Berggren, W. T.; Griep-Raming, J.; Horning, S.; Makarov, A.; Phanstiel, D.; Stafford, G.; Swaney, D. L.; Syka, J. E. P. Zabrouskov, V.; Coon, J. J. A Proteomics Grade Electron Transfer Dissociation-Enabled Hybrid Linear Ion Trap-Orbitrap Mass Spectrometer. J. Proteome Res. 2008, 7, 3127-3136.

47. Li, J. W.; Taraszka, J. A.; Counterman, A. E.; Clemmer, D. E. Influence of Solvent Composition and Capillary Temperature on the Conformations of Electrosprayed Ions: Unfolding of Compact Ubiquitin Conformers from Pseudonative and Denatured Solutions. Int. J. Mass Spectrom. 1999, 187, 37-47.

48. Myung, S.; Badman, E. R.; Lee, Y. J.; Clemmer, D. E. Structural Transitions of Electrosprayed Ubiquitin Ions Stored in an Ion Trap over Similar to $10 \mathrm{~ms}$ to $30 \mathrm{~s}$. J. Phys. Chem. A 2002, 106, 9976-9982.

49. Koeniger, S. L.; Merenbloom, S. I.; Sevugarajan, S.; Clemmer, D. E. Transfer of Structural Elements from Compact to Extended States in Unsolvated Ubiquitin. J. Am. Chem. Soc. 2006, 128, 11713-11719.

50. Koeniger, S. L.; Clemmer, D. E. Resolution and Structural Transitions of Elongated States of Ubiquitin. J. Am. Soc. Mass Spectrom. 2007, 18, 322-331.

51. Segev, E.; Wyttenbach, T.; Bowers, M. T.; Gerber, R. B. Conformational Evolution of Ubiquitin Ions in Electrospray Mass Spectrometry: Molecular Dynamics Simulations at Gradually Increasing Temperatures. Phys. Chem. Chem. Phys. 2008, 10, 3077-3082.

52. Shvartsburg, A. A.; Li, F. M.; Tang, K. Q.; Smith, R. D. Distortion of Ion Structures by Field Asymmetric Waveform Ion Mobility Spectrometry. Anal. Chem. 2007, 79, 1523-1528

53. McLuckey, S. A.; Glish, G. L.; Asano, K. G.; Grant, B. C. Atmospheric Sampling Glow-Discharge Ionization Source for the Determination of Trace Organic-Compounds in Ambient Air. Anal. Chem. 1988, 60, 2220-2227.

54. Him, T.; Tolmachev, A. V.; Harkewicz, R.; Prior, D. C.; Anderson, G.; Udseth, H. R.; Smith, R. D.; Bailey, T. H.; Rakov, S.; Futrell, J. H. Design and Implementation of a New Electrodynamic Ion Funnel. Anal. Chem. 2000, 72, 2247-2255.

55. Valentine, S. J.; Koeniger, S. L.; Clemmer, D. E. A Split-Field Drift Tube for Separation and Efficient Fragmentation of Biomolecular Ions. Anal. Chem. 2003, 75, 6202-6208.

56. Tang, K.; Shvartsburg, A. A.; Lee, H. N.; Prior, D. C.; Buschbach, M. A.; Li, F. M.; Tolmachev, A. V.; Anderson, G. A.; Smith, R. D. HighSensitivity Ion Mobility Spectrometry/Mass Spectrometry Using Electrodynamic Ion Funnel Interfaces. Anal. Chem. 2005, 77, 3330-3339.

57. Julian, R. R.; Mabbett, S. R.; Jarrold, M. F. Ion Funnels for the Masses: Experiments and Simulations with a Simplified Ion Funnel. J. Am. Soc. Mass Spectrom. 2005, 16, 1708-1712.

58. Fuhrer, K.; Gonin, M.; McCully, M. I.; Egan, T. F.; Ulrich, S. R.; Vaughn, V. W.; Burton W. D.; Jr., Schultz, J. A.; Gillig, K. J.; Russell, D. H. Monitoring of Fast Processes by TOF MS. Proceedings of the 49th ASMS
Conference on Mass Spectrometry and Allied Topics; Chicago, IL May, 2001, p. 27-31.

59. Clemmer, D. E.; Jarrold, M. F. Ion Mobility Measurements and Their Applications to Clusters and Biomolecules. J. Mass Spectrom. 1997, 32, 577-592.

60. Loo, R. R. O.; Winger, B. E.; Smith, R. D. Proton Transfer Reaction Studies of Multiply Charged Proteins in a High Mass-to-Charge Ratio Quadrupole Mass Spectrometer. J. Am. Soc. Mass Spectrom. 1994, 5 $1064-1071$

61. Soyk, M. W.; Zhao, Q.; Houk, R. S.; Badman, E. R. A Linear Ion Trap Mass Spectrometer with Versatile Control and Data Acquisition for Ion/Ion Reactions. J. Am. Soc. Mass Spectrom. 2008, 19, 1821-1831.

62. Badman, E. R.; Hoaglund-Hyzer, C. S.; Clemmer, D. E. Dissociation of Different Conformations of Ubiquitin Ions. J. Am. Soc. Mass Spectrom. 2002, 13, 719-723.

63. Mason, E. A.; McDaniel, E. W. In Transport Properties of Ions in Gases; John Wiley and Sons: New York, 1988, p. 86-91.

64. Badman, E. R.; Myung, S.; Clemmer, D. E. Evidence for Unfolding and Refolding of Gas-Phase Cytochrome $c$ Ions in a Paul Trap. J. Am. Soc. Mass Spectrom. 2005, 16, 1493-1497.

65. Koeniger, S. L.; Merenbloom, S. I.; Clemmer, D. E. Evidence for Many Resolvable Structures within Conformation Types of Electrosprayed Ubiquitin Ions. J. Phys. Chem. B 2006, 110, 7017-7021.

66. Zhao, Q.; Soyk, M. W.; Houk, R. S.; Badman, E. R. Effects of Ion/Ion Reactions on Conformation of Gas-Phase Cytochrome c Ions J. Am. Soc. Mass Spectrom. 2009, unpublished; to be submitted.

67. Badman, E. R.; Hoaglund-Hyzer, C. S.; Clemmer, D. E. Monitoring Structural Changes of Proteins in an Ion Trap over 10 to $200 \mathrm{~ms}$ : Unfolding Transitions in Cytochrome $c$ Ions. Anal. Chem. 2001, 73, 6000-6007.

68. Koeniger, S. L.; Merenbloom, S. I.; Valentine, S. J.; Jarrold, M. F.; Udseth H. R.; Smith, R. D.; Clemmer, D. E. An IMS-IMS Analogue of MS-MS. Anal. Chem. 2006, 78, 4161-4174.

69. Merenbloom, S. I.; Koeniger, S. L.; Valentine, S. J.; Plasencia, M. D.; Clemmer, D. E. IMS-IMS and IMS-IMS-IMS/MS for Separating Peptide and Protein Fragment Ions. Anal. Chem. 2006, 78, 2802-2809.

70. Xia, Y.; Liang, X. R.; McLuckey, S. A. Ion Trap Versus Low-Energy Beam-Type Collision-Induced Dissociation of Protonated Ubiquitin Ions. Anal. Chem. 2006, 78, 1218-1227.

71. Breuker, K.; McLafferty, F. W. Native Electron Capture Dissociation for the Structural Characterization of Noncovalent Interactions in Native Cytochrome $c$ Angew. Chem. Int. Ed. 2003, 42, 4900-4904.

72. Breuker, K. McLafferty, F. W. The Thermal Unfolding of Native Cytochrome $c$ in the Transition from Solution to Gas Phase Probed by Native Electron Capture Dissociation Angew. Chem. Int. Ed. 2005, 44, 4911-4914

73. Breuker, K.; McLafferty, F. W. Stepwise Evolution of Protein Native Structure with Electrospray into the Gas Phase, 10(-12) to 10(2) s. Proc. Natl. Acad. Sci. U.S.A. 2008, 105, 18145-18152. 